\title{
La experimentación pedagógica territorial y la democratización del sistema educativo. Lecciones del Plan Experimental de Educación Rural de San Carlos (1944-1947)
}

\author{
Graciela Rubio a \\ Luis Osandón ${ }^{b}$ \\ Francisca Quinteros c
}

\section{Resumen}

Se analiza una experiencia democratizadora y descentralizada del cambio educativo basada en la educación experimental que integró aspectos formativos, culturales, sanitarios, la participación de la comunidad y el apoyo integral del Estado a niños y jóvenes del mundo rural para superar la pobreza y marginalidad. El Plan Experimental fue un intento de regulación social coherente con el modelo de desarrollo sustitutivo de importaciones y la democratización de las relaciones sociales, pero no previó la resistencia de sectores conservadores locales y nacionales quienes bloquearon su ejecución al verlo como una amenaza al orden social rural de la época. Evidencia también, las dificultades históricas en Chile para desarrollar una política educativa descentralizada con base territorial, aportando a la reflexión sobre la reorganización actual del sistema público de educación en unidades administrativas y de gestión territorial llamada Servicios Locales de Educación, orientados a eliminar la descentralización administrativa neoliberal. Palabras clave: Reformas educativas. Descentralización. Experimentación pedagógica. Democratización.

\footnotetext{
a Universidad de Valparaíso, Instituto de Historia y Ciencias Sociales, Valparaíso, Chile.

b Universidad de Chile, Departamento de Estudios Pedagógicos, Santiago, Chile.

c Red-Q, Corporación, Corporación de Educación Pública de Quillota, Quillota, Chile.
} 


\section{Introducción}

A mediados del siglo XX el Estado chileno vivió importantes transformaciones de la mano de gobiernos liderados por el Partido Radical que en alianza con otros partidos de izquierda, asumieron un modelo de desarrollo basado en la industrialización sustitutiva de importaciones, orientado por un ideario nacionaldesarrollista. Esto los llevó a impulsar políticas democratizadoras de la sociedad, procurando a la vez, integrar el Campo Educativo con el productivo (HENRÍQUEZ, 2014; MOULIÁN, 2006; TIRONI, 1983).

Es propósito de este artículo es indagar en una experiencia específica, que muestra un ángulo interesante para el análisis de los derroteros de la política educacional chilena de mediados del siglo XX. Esto resulta particularmente relevante en medio de un debate en curso sobre la reorganización del sistema educativo público chileno, para el que se propone la creación de estructuras administrativas intermedias entre el nivel municipal actual y el nivel central correspondiente al Ministerio de Educación. El nuevo modelo de organización, denominado Sistemas Locales de Educación (SLE), pretende agrupar escuelas de uno o más municipios, bajo un mismo aparato de gestión y desarrollo de los procesos educativos. Su propósito es "sentar las bases para renovar y fortalecer la escuela pública chilena; comprometiendo la responsabilidad del Estado y otorgándole, como condición primera y urgente, una institucionalidad adecuada y moderna" (REPÚBLICA DE CHILE, 2015, p. 2). Pretende recuperar el protagonismo del Estado en la provisión del servicio educativo a casi cuatro décadas de un modelo de mercado educativo en que las escuelas públicas compiten por estudiantes junto a las privadas subvencionadas por el Estado.

Parece inevitable analizar la experiencia histórica chilena sobre procesos de descentralización educativa. Particularmente, el Plan San Carlos nos permite abordar las siguientes preguntas frente al presente: ¿Cómo se valoró y argumentó el desarrollo educativo territorial por la clase política?; ¿Qué factores favorecieron o dificultaron las experimentaciones pedagógicas a escala local?; ¿Cómo se expresó una política orientada a la democratización de la sociedad en el territorio local?

Para comprender esta novedosa iniciativa de política educacional centrada en el territorio local, debemos señalar que, a partir de 1938, con la llegada al poder de la alianza de partidos de izquierda denominada Frente Popular (1936-1941), el Estado impulsó un modo de actuación caracterizado por un doble movimiento de transformación y contención de los procesos sociales, tomando la iniciativa para promover cambios en los modos de vida de la sociedad chilena, e instalando la idea de la democratización como un valor fundamental para el desarrollo económico (HENRÍQUEZ, 2014; ILLANES, 2006; 2010). 
Esta lógica de actuación se incorporó en el Campo Educativo. Los estudios sobre el período desde la perspectiva educacional, lo han abordado principalmente desde sus aristas políticas (ESCOBAR, 1996; ESPINOZA, 1989; MARTNER, 1986), educativo-políticas (CASTRO-PAREDES, 2012; NÚÑEZ, 1989; 1995; OSANDÓN, 2007; ZEMELMAN; JARA, 2006) y gremiales (NÚÑEZ, 1986). También se han realizado algunas aproximaciones más específicas a sus aristas socioculturales, como aproximación simbólica sobre algunas de sus políticas (TORO, 2015) o, como indagación sobre prácticas docentes y vida cotidiana escolar (OSANDÓN, 2007; URETA, 2015). En la mayoría de los casos, y sobre todo desde una perspectiva de políticas educativas, el Plan Experimental de San Carlos ha sido abordado como un evento relevante para entender el surgimiento de las Escuelas Consolidadas de mediados del siglo XX (REYES et al., 2013; VIDELA, 2010). Sin embargo, la imagen que ha predominado es su particularidad como expresión de una reforma educativa a escala local (ZEMELMAN; JARA, 2006; NÚÑEZ, 1986). Hasta el momento, no hay disponible un análisis que se focalice específicamente en la propuesta y desarrollo del Plan; nuestro propósito es ofrecer un primer esfuerzo de profundización sobre esta experiencia de política de cambio educacional.

El Plan constituye un caso de diseño de intervención social desde el enfoque experimental, acotado a un territorio rural, introduciendo una especial y nueva relación entre Estado y Campo Educativo, caracterizada por la articulación explícita entre educación y sociedad. Esta experiencia es abordada en los apartados siguientes considerando sus aristas sociales, culturales, políticas y educativas.

\section{Perspectiva teórica del análisis}

Para efectos de nuestro análisis, hemos tomado las ideas de Popkewitz (2000), quien ha propuesto un marco de interpretación de las reformas educativas modernas, proponiendo cuatro categorías analíticas: regulación social, epistemología social, instituciones y campo.

La categoría de regulación social evidencia los elementos activos del poder en ejercicio. Describe el fenómeno del control desde una perspectiva abierta y dinámica en cada uno de los contextos ecológicos por los cuales transitan los sistemas educativos. Las reformas y sus discursos de cambio y mejora social son excelentes coyunturas en que se puede apreciar con mayor nitidez, las fuerzas enmarcadas en las relaciones de "saber-poder" (Foucault), que operan en cada intento de regulación social.

La categoría epistemología social, aborda las discusiones teóricas sobre la noción de educar, sus adaptaciones y los modos en que se vuelven norma en las 
instituciones. Esta conceptualización permite "pensar el pasado en el presente": problematizar históricamente la continuidad y discontinuidad de los fenómenos en las reformas, develando las formas de conceptualización, los marcos teóricos de estas nominaciones y las construcciones políticas que emergen una vez que entran en interacción con el Estado para el diseño de estrategias de cambio educativo.

Luego, la categoría Instituciones refiere a un espacio activo en el cual se vinculan la epistemología social y la regulación social. Es un recurso metodológico para analizar cómo se discute y resuelve la epistemología social, las prácticas sociales y la configuración del Campo Educativo. Permite analizar en perspectiva, las diversas formas de institucionalidad generadas en los procesos de reforma.

Por último, la categoría Campo, tomada de Bourdieu (1980), basada en una concepción relacional y dinámica del poder, muestra cómo en el ámbito educativo, en un momento histórico dado, las relaciones entre instituciones y actores convergen para producir distinciones y diferenciaciones sociales. La categoría es pertinente para establecer la continuidad y discontinuidad de las relaciones entre Estado, campo educativo y sociedad civil.

Este artículo muestra a través de la retórica política y técnica debatida, cómo se manifestó el proceso de regulación social, entendida como poder activo, en la implementación del Plan y al mismo tiempo, el análisis de la epistemología social subyacente a su activación y a su posterior eclipse como experiencia de innovación educacional.

\section{Juan Antonio Ríos: el campo educativo y la democratización del sistema escolar}

El gobierno de Ríos (1942-1946), con su lema, "Gobernar es producir” se constituyó en medio de un complejo escenario de alianzas políticas, agudizado tras la disolución del Frente Popular y la muerte prematura del presidente Aguirre Cerda (1941). La candidatura de Ríos prometió un "gobierno nacional", intentando prescindir del énfasis político de izquierda del gobierno de Aguirre Cerda, pero conservando las ideas matrices de desarrollismo y de las políticas para una mayor justicia social y respeto a la dignidad humana (RÍOS, 1942). Durante su gobierno se abrieron espacios de participación para diversos actores del Campo Educativo, enfatizando la igualdad y la democracia como propósitos centrales de su quehacer.

Tanto Aguirre Cerda (1938-1941) como Ríos, compartieron una comprensión de la trascendencia del Estado Docente y vieron en la educación una vía rápida 
y focalizada para articular la formación de ciudadanos con la educación para el trabajo. Cómo lo ha señalado ILLANES (2006), la "política social" de esos años se inscribía en una tendencia a profesionalizar la intervención civil y estatal sobre los pobres y los trabajadores, tanto para mejorar sus condiciones de vida, como para prevenir el daño e incorporarlos al proyecto nacional.

Por su parte, el Campo Educativo, tal como lo muestra la Revista de Educación entre 1940-1944, evidenciaba cada vez mayor consolidación de la mano del desarrollo de las ciencias de la educación y la pedagogía, marcando el período 1939-1957 (NÚÑEZ, 2002). Un tránsito desde el ensayismo pedagógico a la pedagogía experimental, remató hacia fines de la década del cincuenta en los primeros ejercicios de planificación sistémica de las reformas educativas. Este proceso de complejización del Campo, que fue amasando ideas de distinta procedencia, la mayoría de ellas caracterizadas por el énfasis en la democracia y el desarrollo, tendría un giro importante tras finalizar la Segunda Guerra Mundial, dada la fuerte hegemonía de Estados Unidos sobre el continente latinoamericano. Fue así como tomaron un mayor énfasis las perspectivas eficientistas de los procesos educativos, los que no tardaron en hacerse hegemónicas en la discusión educativa local en las décadas siguientes. Vale decir, las décadas de 1940 y 1950 fueron años especialmente sensibles a la reconfiguración de la incipiente ciencia educativo-pedagógica de la época (NÚÑEZ, 2002).

Hacia mediados de la década de 1940, los conceptos dominantes de la política educativa estaban organizados en torno a la idea de función social de la educación, que integraba en términos pedagógicos y prácticos los principios de educación pública, bienestar, protección, trabajo, progreso económico, igualdad de oportunidades y democracia. Estos referentes fueron asumidos, en los acuerdos de los docentes, en el marco de la Renovación de la Educación Secundaria en la coyuntura 1944-1946, la cual evidenció una creciente integración discursiva entre lo social, lo político, lo económico y lo científico. Así, la “tecnificación” y la “experimentación” operarían como articuladores pedagógicos para la regulación social dirigida por el Estado Docente.

Por otra parte, es interesante resaltar que el uso del concepto experimentación en el discurso pedagógico de la época tuvo un carácter multidimensional y un fuerte énfasis sociocultural. Se le asoció como estrategia de enseñanza-aprendizaje en el aula, como orientadora de la libertad del estudiante, al uso de habilidades investigativas y al desarrollo de actitudes valorativas de la democracia. Para todo esto, se requería:

[...] crear un ambiente propicio donde cada niño pueda vivir su propia vida: pensar, resolver sus propios problemas; bastarse a sí 
mismo, y cooperar con sus demás compañeros en las actividades de la comunidad escolar. [...] Solo así adquirirá el concepto de la responsabilidad, así sabrá ser libre y podrá ser solidario; así será un miembro eficiente en la democracia (LATORRE, 1945a, p. 39-40).

Así, la integración en la vida democrática implicaba asumir la dimensión experiencial del sujeto y su futura interacción en el campo social. Siguiendo a Popkewitz (2007), la dimensión política de la experimentación se basó en la articulación entre la idea de comunidad de iguales pre existente (Gemeinschaft), que se usó como recurso para pensar la vida futura en la sociedad industrial; y la idea de sociedad entendida como leyes, convenciones y el dominio de la opinión pública (Gesellschaft). La reforma basada en la experimentación, con una comunidad por construir, debía apoyarse en los actores del Campo Educativo, en el Estado Docente, en la noción de protección de la comunidad y en la ciencia como fundamento para la normatividad del proceso educativo. Al respecto, Latorre se preguntaba:

¿Cómo puede adquirir fe democrática un niño que sufre la violencia de un sistema escolar anacrónico que durante 6 años lo somete a obediencia ciega? ¿Cómo puede predicar fe democrática un maestro que vive durante 30 años en flagrante conflicto entre pensamiento y acción? Y luego, si la democracia significa convivencia social, organización solidaria, cooperación, vínculo, reconocimiento mutuo de intereses, ¿cómo formar actitudes democráticas en un ambiente en que todo está orientado hacia el aislamiento y el individualismo? (LATORRE, 1945b, p. 472).

En el contexto de estas evidentes tensiones entre escuela, comunidad y normatividad, la dimensión estratégica de la idea de experimentación suponía un conjunto de acciones del gobierno para la instalación de reformas de las prácticas educativas locales de la escuela. La realización de las ideas pedagógicas más arriba descritas implicó sortear un contexto político complejo, dados los continuos conflictos de los partidos que apoyaban al Gobierno, la escasez de recursos fiscales y las resistencias de la derecha parlamentaria para ampliar las cuotas de igualdad de oportunidades en el sistema educativo.

\section{El surgimiento del plan de educación rural en San Carlos y sus tensiones}

El Plan San Carlos, fue un ensayo local para buscar alternativas de desarrollo de la educación pública en el contexto rural, ello con la expectativa de modelar una reforma educativa a nivel nacional y de responder al derecho a la educación. 
El inicio de la experiencia se concretó a través de la publicación del Decreto $\mathrm{n}^{\circ}$ 3.654 de 1944, que declaró a la jurisdicción escolar de San Carlos, provincia de Ñuble, "zona experimental”. Le siguieron a esta medida la aprobación del Plan de Experimentación por medio del Decreto n 1.100 de marzo de 1945 que contempló la creación de siete instituciones escolares: una Escuela Normal Rural, una Escuela Anexa a la Normal (de Concentración), una Escuela de Salud, una Escuela Consolidada, una Escuela de Cultura Popular y una Escuela Granja. La primera escuela en crearse fue la Escuela Consolidada, orientada a facilitar la continuidad de estudios desde el nivel parvulario al secundario, proveyendo todas las alternativas de estudio en la misma institución. Su objetivo principal fue evitar la deserción escolar por falta de oportunidades y favorecer el tránsito desde el nivel primario al secundario. Al respecto las cifras iniciales fueron alentadoras; en 1945, 68 estudiantes pasaron del nivel primario al secundario, dos años más tarde, la cifra había subido a 320 .

En coherencia con lo anterior, la Escuela Normal Rural estaba pensada como un modo de formar docentes en y para el contexto rural. Sobre esto el senador radical Carlos Alberto Martínez, en un informe al Senado en 1947, apoyaba esta idea señalando que el estudiante de pedagogía de esa Normal "será de auténtica extracción campesina [...] será el guía, el orientador, el animador del medio en que desarrolle sus actividades"1. Del mismo modo, el senador destacaba el rol de la Escuela Anexa a la Normal, que contaría con internado, talleres y actividades agropecuarias y en un corto plazo, con Departamentos Médico-Social, PedagógicoSocial y de Extensión Cultural; a lo que se sumaría una Escuela Ambulante que cumpliría la función de repartir cultura tanto a niños como adultos en todo el territorio; y una Escuela de Salud, que se ubicaría en el pueblo cordillerano de San Fabián, con el objetivo de promover la recuperación sanitaria de los niños más débiles. En síntesis, se sostenía que el Plan debía “[...] concentrar las múltiples e intrascendentes escuelas rurales en poderosas instituciones educacionales, dotadas de todos los elementos necesarios para servir al medio rural en sus problemas y necesidades"2.

Desde una perspectiva más amplia, el Plan incorporó gran parte de los principios del pensamiento educativo "funcionalista", el cual había integrado los planteamientos largamente reflexionados por el profesorado desde la década de 1920 sobre las características requeridas por nuestro sistema educacional. Esto implicaba aspirar a un sistema integrado ya propuesto para la reforma educativa de 1927; éste, debía caracterizarse por su unidad (correlación y continuidad desde la Primaria a la

\footnotetext{
1 MARTínEZ, C. Diario de Sesiones, Legislatura Ordinaria, Sesión No 33, 13 de mayo de 1947, p. 1462.

2 MARTínEZ, C. Diario de Sesiones, Legislatura Ordinaria, Sesión № 33, 13 de mayo de 1947, p. 1462.
} 
Universidad), Autonomía (económica, técnica y administrativa de la institución educativa); participación de la comunidad (padres, hijos y maestros), coeducación y descentralización (NÚÑEZ, 2013).

El Plan San Carlos fue liderado por Víctor Troncoso, antiguo dirigente de la Asociación Gremial de Profesores (AGP) y protagonista de la reforma de 1927, quien ahora como Inspector Escolar, dirigió y defendió la pertinencia del Proyecto y la necesaria proyección de la experiencia a escala nacional.

Para efectos de la implementación de la Zona Experimental de San Carlos, Troncoso, junto a otros profesores, como Vicente Recabarren, reclutaron destacados profesores provenientes de diversas partes del país. Animados por las ideas de la Escuela Nueva y por la posibilidad de llevar adelante una experiencia innovadora, que articulara efectivamente la relación entre escuela, comunidad y territorio, los profesores que se vincularon al proyecto tuvieron problemas desde el inicio, sufriendo el estigma de "afuerinos". El profesorado local recibió con recelo esta experiencia y fue evidente el quiebre entre éstos y el equipo de profesores que llegó a la ciudad. Del mismo modo, evidencias de fragmentación de la experiencia, muestran que la Escuela Consolidada organizada en San Carlos, si bien fue su eje central, su concreción de la cobertura rural y de las instituciones de apoyo no llegó a niveles muy significativos. Por último, parece haber contribuido al lento avance de la experimentación, el carácter autoritario de la conducción de Víctor Troncoso (OSANDÓN, 2007).

Desde otro ángulo, la experimentación produjo diversas reacciones en los actores de la localidad, interesando, a favor y en contra, a partidos políticos, instituciones y la comunidad. En general estos actores valoraban la importancia de esta experiencia para "el desarrollo cultural" de San Carlos; pero siempre hubo diferencias. En un reporte sobre el desarrollo del Plan, hacia 1947, el senador Salvador Allende destacaba, quizás no muy enterado de las disputas internas del cuerpo de docentes a cargo de la experiencia, que:

El profesorado cuenta además con estimación del pueblo, ganada a través de su trabajo tesonero e inteligente. Cabe destacar que el magisterio ha sabido estimular el espíritu público de la población [...] estableciéndose como lógica consecuencia la cooperación que el Plan ha recibido en su desarrollo ${ }^{3}$.

ALLENDE, S. Informe citado en Diario de Sesiones, Legislatura ordinaria, 1947, p. 1.106. 
Más allá de los problemas de conducción y de las diferencias internas entre los profesores, la experimentación produjo un interesante efecto de participación y autonomía de "los propios", es decir, de los campesinos, designados de esa manera por los terratenientes como una forma de reafirmar la relación de sometimiento y sujeción en la cual vivían por ese entonces. Los campesinos, destinatarios principales de esta nueva experiencia educativa, participaron activamente como apoderados en un nuevo marco de relaciones educativas, que los dignificaba y les legitimaba como actores relevantes en la educación de sus hijos. Ello en clara discrepancia con las formas jerárquicas propias del latifundio chileno.

Una acción educativa territorializada no puede entenderse si no es con la activación de las voluntades y saberes de la población local, y como era de esperarse, la intervención territorial contemplada en el Plan alarmó, por su potencial transformador de las relaciones sociales, a diversos actores en distintos niveles y por diversos motivos.

Hacia 1947, una carta firmada por los dirigentes de los partidos Radical, Falangista, Liberal, Conservador, Agrario-Corporativo y Agrario Laborista, expresó esta alerta pidiendo la remoción del jefe del Plan, el normalista Víctor Troncoso:

De acuerdo a las ideas generales de la democracia y en especial con las doctrinas de los partidos que representamos, [queremos] solicitar que se suprima en el Plan de Experimentación Educacional la acción política de la escuela, implantada por el señor Troncoso y sus colaboradores inmediatos; de manera que la escuela sea centro de enseñanza y de cultura al servicio de la sociedad y no un centro político de acción social prepotente y negativa. Manifestar nuestro deseo de que resten al Inspector Escolar de esta Zona Experimental las facultades omnímodas de que este funcionario se encuentra investido en virtud del artículo 8 del Decreto 1.100, pudiendo de acuerdo con el artículo citado, poner en disponibilidad a quien quiera de sus subalternos, sin otro sujeción que su propia voluntad, que podría haber sido justa, pero que ha resultado apasionada y vengativa en los numerosos casos de traslados que se han sucedido, existiendo una verdadera dictadura contra el profesorado del Departamento ${ }^{4}$.

El mismo senador Allende reconoce que, de los 56 maestros que había en San Carlos, 14 eran socialistas. Lo que muestra que efectivamente la variable clientelar de los partidos estaba presente en la toma de decisiones, interviniendo

\footnotetext{
${ }_{4}$ Carta citada por Allende, S. Diario de Sesiones, Legislatura ordinaria, 1947, p. 1.106
} 
y reduciendo el proyecto y sus tensiones a una disputa de los partidos socialista y radical. En este escenario, los sectores de derecha no trepidaron en radicalizar sus apreciaciones sobre el Plan.

[...] lo que con tanta prosopopeya se anunciaba como adelanto técnico, no era sino una pantalla para disimular una labor de carácter exclusivamente político! [...] todo lo demás era sólo palabrería; [...] el Sr. Troncoso no solo era proselitista sino perseguidor, e iba tras su finalidad política sin miramientos ni contemplaciones. ${ }^{8}$

El senador Errazuriz en la misma discusión remataba diciendo que del caso no se habría sabido si es que Troncoso no hubiese despedido a los profesores radicales y contratado a los socialistas, "[...] nada hubiese sucedido si hubiesen seguido dividiéndose el feudo educacional de esa zona entre socialistas, radicales y comunistas, como lo han hecho durante años en el resto del país" ${ }^{5}$

Allende denunció los intereses políticos de dirigentes radicales locales, que en el marco de las elecciones parlamentarias que se avecinaban habían actuado "de acuerdo a intereses bastardos de predominio" y "se ha querido jugar con el Plan San Carlos como una manera de consolidar intereses de pequeños candidatos"“. Así las cosas, en la discusión del presupuesto para el año 1948, el sector conservador negó el financiamiento al Plan aduciendo, entre otras cosas, que éste estaba destinado a financiar un sobresueldo para el profesorado ${ }^{7}$. También se denostó a Troncoso, argumentando esta vez desde "lo técnico", la necesidad de contar en ese lugar con alguien con la competencia profesional para liderar el proyecto. Se dijo que Troncoso, al ser un profesor normalista, carecía de habilidades para dirigir el Plan. Dicha distinción, dada la constitución socio histórica del sistema educativo y de los centros de formación de profesores vigentes, tenía una clara connotación de clase.

"Dije en esta sala, corroborando lo que había manifestado en la Comisión Mixta de Presupuestos, que el Sr. Troncoso era la persona menos adecuada para dirigir el experimento; que no se le conocía éxito alguno en su carrera; que se sabía que dos veces había sido Director de Escuela Normal y las dos veces había tenido que ser destituido. (...) Era inaudito que un Inspector Escolar tuviese las funciones propias de un Ministro."

\footnotetext{
ERRÁZURIZ, M. Diario de Sesiones, Legislatura ordinaria, 1947, p. 1.112.

ALLENDE, S. Diario de Sesiones, Legislatura ordinaria, 1947, p. 1.106.

ERRÁZURIZ, M. Diario de Sesiones, Legislatura ordinaria, 1947, p. 1.111.

s ERRÁZURIZ, M. Diario de Sesiones, Legislatura ordinaria, 1947, pp. 1.111-1.112.
} 
Hay que tener en cuenta que por esos años el profesorado organizado contaba con una fuerte influencia y reconocimiento, como un magisterio autónomo y activo, de ahí que los conservadores vieran en cualquier atisbo transformativo del sistema educacional una "intromisión de la política en las aulas", y en este caso, bajo el amparo del Gobierno?.

A lo anterior, habría que agregar que muy en sintonía con los partidos de derecha, la Iglesia católica se opuso apelando a la Constitución y a la defensa de la libertad de enseñanza, señalando que esta última era una de las más "bellas concepciones democráticas", y que según sus orientaciones, el Plan estaba en "pugna violenta con las bases de religión, patria y familia que la sociedad y el pueblo chilenos han aceptado ya secularmente en la dirección espiritual de sus hijos" ${ }^{10}$.

En síntesis, entre los problemas del Plan San Carlos que condujeron a su derrota, estuvo la debilidad derivada de las propias acciones de los protagonistas de la experimentación, quienes en la micropolítica de la gestión escolar, demostraron que la instalación de una innovación sin negociar significados con los actores, produciría rápidamente resistencias y eventuales sabotajes internos. Por otra parte, las guerrillas locales entre partidos altamente sensibles a las políticas centralistas, pese a declarar su apoyo ideológico a esta novedosa propuesta, terminarían bloqueando su ejecución. Finalmente, de un modo insospechadamente protagónico, los cuestionamientos políticos entre un polo progresista y otro conservador tomarían ribetes de disputa ideológica nacional parlamentaria sobre la conveniencia de esta experimentación en un espacio acotado. Un asunto local se convertía así en uno de disputa nacional; esto no se explicaría si no fuera por el impacto transformador de la experimentación en el orden social rural.

\section{El ocaso de la experimentación}

La muerte prematura del presidente Ríos en 1946 dejó sin protección política al proyecto experimental, esto, unido a las diferencias internas relacionadas con su ejecución, a la crítica de los partidos tradicionales que buscaban imponer lógicas de control de carácter centralista, y al rechazo de sectores conservadores de la zona a su implementación, produjo una dinámica de cuestionamiento de múltiple origen y envergadura, pero que en el total facilitaron argumentos para disminuir el financiamiento destinado a su ejecución; esto hasta hacer inviable su idea original. Razones propias de los poderes locales, unidas a la adhesión del nuevo presidente Gabriel González Videla a la política norteamericana de

\footnotetext{
9 Diario, La Unión, Valparaíso, 9 de abril de 1944.

10 Diario, La Unión, Valparaíso, 8 de abril de 1944.
} 
postguerra, caracterizada por la imposición de orientaciones técnicas en el Campo Educativo y por una visión globalizada de las reformas educativas asociada al planeamiento y la profesionalización del trabajo de las escuelas, acabarían clausurando el Plan en 1947.

Allende evidenció explícitamente el carácter político de la decisión de no continuar el Plan, pues el Ministro de Educación de ese momento, Alejandro Ríos Valdivia, le confesó que "por desgracia, en este país vivíamos en una era de influencia política y que él, hombre que actuaba en la vida política, tenía que someterse forzosamente a los dictados de su partido y que esto era lo que le obligaba a alejar de su puesto al Sr. Troncoso"

El enfoque que propiciaba el vínculo activo entre docente y comunidad había amenazado las bases del orden oligárquico del territorio rural. Esto quedó particularmente evidenciado cuando el Gobernador de la zona ordenó disolver, mediante decreto, los Centros de Padres de Familia organizados en torno a la Escuela Consolidada. Si bien la medida fue revertida por la protesta del Director General de Educación Primaria, enviada a los ministros de Interior y Educación, el hecho mostraría las tensiones sociales que provocaba la organización de los campesinos como actores activos en el aprendizaje de sus hijos e hijas.

En 1947, se discutió definitivamente el cierre del proyecto, para ello se adujeron razones administrativas y presupuestarias. El Ministro de Educación, consideraba que una Escuela Normal en el Plan San Carlos no se justificaba, dado que el propio presidente Ríos en 1942 había creado escuelas normales cercanas a la localidad en Victoria y Talca mediante Decreto n. $^{\circ} 1.185$. Por lo mismo, propuso reducir la propuesta original solo a la Escuela Consolidada, para "[...] poner las finalidades del Plan en absoluto acuerdo con la política educacional del Gobierno"12.

En tanto, la comisión evaluadora del Plan estimó que, al proponerse la orientación vocacional en la Primaria, se oponía de modo irreductible el medio rural con el urbano y se desconocía la función específica de la Escuela Primaria de "impartir cultura general". Este juicio evaluativo negaba uno de los principios fundamentales de la experiencia, esto es, la articulación entre todos los niveles educativos como política de igualdad de oportunidades. En el mismo sentido, el senador conservador Errazuriz cuestionaría el principio democrático de la continuidad de estudios y sus efectos en la movilidad social.

\footnotetext{
11 ALLENDE, S. Diario de Sesiones, Legislatura Ordinaria, 1947, p. 1.101.

12 RíOS VALDIVIA, A. Diario de Sesiones, Legislatura ordinaria, 1947, p. 1.088.
} 
¿qué ventaja había en que los niños entraran a esa escuela y no a un liceo común? Comprendo que pueda ser convincente prolongar la obligación escolar más allá del Sexto Año de Educación Primaria, en beneficio de una instrucción complementaria, que enseñe un arte o un oficio, ya que lo que el país necesita son obreros especializados: pero hacer que el niño ingrese a Primero o Segundo año de Humanidades, en la certeza absoluta de que va a quedar en el camino, sin terminar esas humanidades, como está quedando hoy día la mayor parte de la juventud chilena, no me parece que constituya un progreso desde ningún punto de vista ${ }^{13}$.

En suma, el Plan San Carlos evidenciaría nítidamente la tensión generada entre la nueva estructura educativa territorial propuesta y el Estado centralizado. La apuesta descentralizadora territorial chocó con la institucionalidad y la tradición centralista, generando una superposición de funciones que tensionaría la administración fiscal (NÚÑEZ, 1986). A ello se debe agregar que el Plan fue financiado con partidas no contempladas en los gastos presupuestados, lo que desde sus orígenes lo situó en posición de vulnerabilidad.

En síntesis, el Plan evidenció una débil preparación para su eficaz instalación y, por lo tanto, sus alcances y efectos fueron limitados y acompañados por la resistencia de sectores proclives a la conservación del orden preexistente (NÚÑEZ, 1995, p. 176). Una estructura administrativa educacional de un Estado fuertemente centralizado, se conjugó con una suerte de "ilusión del modelo" (NUÑEZ, 1995), es decir, por un excesivo entusiasmo por las cualidades del diseño de la experimentación, que apostó un poco ciegamente por su fuerza discursiva y por el clima a favor de la democratización de la sociedad en la época. Ello, sin integrar en ese análisis el rol de las estructuras administrativas y la profundidad de los procesos socio culturales involucrados.

\section{Balance y reflexiones}

El proyecto de reforma educativa a escala local se inscribe en un intersticio histórico en que el gobierno radical de Ríos asumió el enfoque pedagógico de la experimentación para articular la protección social y el desarrollo económico. En perspectiva, dicho enfoque formaba parte de una estrategia de regulación social, un cambio educativo orientado a formar nuevos trabajadores y ciudadanos en el marco del Estado de Compromiso y del proyecto desarrollista en ciernes. Si bien el Plan no tuvo continuidad, por las razones ya evidenciadas en el estudio, la

13 ERRÁZURIZ, M. Diario de Sesiones, Legislatura ordinaria, 1947, p. 1.111. 
propuesta permite establecer algunos puntos para la reflexión sobre las condiciones de base que deben considerarse para una articulación e implementación eficaz de una política educativa basada en lo territorial.

El Plan introdujo una epistemología social del enfoque pedagógico experimental basada en una concepción multidimensional del cambio educativo, tanto en lo estratégico como en lo práctico y lo político. Propugnaba la democratización de la sociedad sustentada en un diagnóstico socio económico y en un proyecto político orientado hacia el desarrollo. Del mismo modo, el trabajo territorial basado en el aprendizaje y la protección social, consideraba la educación como habilitadora de un nuevo tipo de trabajador y una nueva conciencia política para la transformación social.

En términos estratégicos, el Plan se consideró como una política educativa para intervenir la sociedad rural y orientarla hacia un modelo productivo de base desarrollista y democratizador. En términos prácticos, la enseñanza se basaba en una concepción ampliada y pragmatista del conocimiento, que relevaba al sujeto/estudiante con capacidades para participar en su construcción desde la experiencia situada. Y desde lo político, éste mismo fue considerado como un ciudadano potencial, inscrito en una comunidad imaginada de iguales, en la cual debía participar activamente.

Esta modalidad de experimentación generó una tensión al interior del campo educativo de la época, en tanto éste carecía de antecedentes históricos y de experiencias institucionales que proveyeran conocimiento previo para su implementación. La posibilidad de desarrollar el componente político del proyecto, a una escala territorial y colectiva, presentaba una debilidad estructural de entrada. La ausencia de experiencia socio histórica, bloqueaba la comprensión y práctica de la idea de compromiso ciudadano de las familias y de la comunidad, en general. Esto afectó la viabilidad del proyecto haciéndolo depender directamente de la correlación de fuerzas políticas del momento.

La propuesta apostaba por una relación activa entre la política educativa y el territorio. Esto implicaba que los docentes debían articular una relación dinámica con la comunidad organizada y, por lo tanto, romper con el modo central-estatal jerarquizado de la administración de la organización institucional del proceso educativo; cuestión que finalmente no se logró a la luz de las evidencias de cómo esta experimentación escaló rápidamente para convertirse en un problema político nacional. Las reacciones de oposición de la clase política local y nacional expresaron su resistencia a reconocer la autonomía al territorio experimental, 
lo que muestra la debilidad del Estado para transferir y generar conocimiento y poder alternativo a nivel local (CASTRO PAREDES, 2010).

En la actualidad, el Estado chileno se encuentra reorganizando el servicio de educación pública, generando agrupaciones de administración y gestión de las escuelas públicas que tienen un alcance territorial mayor al de los municipios. Esta nueva organización actualiza la discusión sobre cómo el Estado se relaciona con las comunidades locales, de qué modo las dinámicas de estos actores pueden favorecer u obstaculizar el fortalecimiento de proyectos educativos territoriales y cómo se puede aspirar a procesos educativos democratizadores para el acceso a conocimientos y herramientas que dinamicen y transformen la segmentada estructura educativa y social chilena (DONOSO et al., 2015).

El Plan San Carlos, plantea la necesidad de considerar las dificultades que ha tenido el Estado chileno para transferir poder efectivo a estructuras de administración intermedia. Los municipios, desde la década de 1980, han mostrado su ineficiencia para solventar la provisión del servicio educativo, más aún, cuando han sido sometidos a la competencia por matrículas en iguales o peores condiciones que las escuelas privadas subvencionadas por el Estado. El resultado ha sido una alta segmentación e inequidad de los logros educacionales, en perjuicio de la educación pública.

A pesar de lo breve de la experimentación en la zona de San Carlos, ella deja algunas lecciones importantes para el presente. Lo primero es que la administración local de la educación pública deberá desarrollar un importante trabajo de articulación política y cultural con la comunidad. Ello incluye a actores estatales, comunitarios y económicos, los que deberán muy probablemente, reaprender el significado de lo público, de su centralidad, de la necesaria coordinación sistémica en torno a lo educativo-público, enriqueciendo los procesos educativos que emprendan las escuelas dependientes de un SLE. Al igual que en San Carlos, ello implicará también, tomar los resguardos frente a la gestión y transferencia del conocimiento y a las resistencias de actores locales y nacionales, que verán en la rearticulación de la educación pública una amenaza a los valores y políticas de la educación mercantilizada resultante del proceso de municipalización vigentes desde la década de 1980. Sin duda, esto no será tarea de la escuela como unidad individual, sino de la fortaleza y amplitud de perspectiva con que se constituyan y de cuan vinculados al territorio se desarrollen los SLE. 


\section{A experimentação pedagógica territorial e a democratização do sistema educacional. Lições do Plano Experimental de Educação Rural de San Carlos (1944-1947)}

\section{Resumo}

A democratização e a experiência descentralizada da mudança educacional baseada na educação experiencial é objeto de análise neste artigo. Integrou aspectos educacionais, culturais, de saúde, de participação da comunidade e contou com apoio estatal abrangente para beneficiar crianças e jovens de áreas rurais para contribuir com a superação da pobreza e a marginalização. O Plano experimental foi uma tentativa coerente de regulação social como modelo alternativo de desenvolvimento e democratização das relações sociais, mas não previu a resistência dos conservadores locais e nacionais que impediram a sua execução por considerarem uma ameaça para a ordem social rural da época. As evidências e as dificuldades históricas no Chile para desenvolver uma politica de educação descentralizada e territorializada, contribuíram para a reflexão sobre a atual reorganização do sistema de educação pública em unidades administrativas e de gestão territorial chamado Serviço de Educação local, destinado a eliminar a descentralização administrativa neoliberal.

Palavras-chave: Reformas educacionais. Descentralização. Experimentação pedagógica. Democratização. 


\title{
The territorial pedagogical experimentation and the democratization of the educational system. Lessons from the Rural Education Experimental Plan of San Carlos (1944-1947)
}

\begin{abstract}
A democratizing and decentralized experience of educational change based on experimental education is analyzed. This experience integrated training, cultural and health aspects, the participation of the community and the integral support of the State to children and young people of the rural world to overcome poverty and marginality conditions. The experimental Plan was an attempt of social regulation consistent with the import substitution development model and the democratization of social relations, but that it did not foresee the resistance of local and national conservative sectors who blocked its execution by seeing it as a threat to the rural social order of the time. It also evidences the historical difficulties to develop a decentralized and territorial education policy in Chile, contributing to reflect on the current reorganization of the public education system in administrative units and based on territorial management, called Local Education Services, aimed at eliminating the neoliberal administrative decentralization.
\end{abstract}

Keywords: Educational reforms. Decentralization. Pedagogical experimentation. Democratization. 


\section{Referências}

BOURDIEU, P. Le sens pratique. París: Minuit, 1980.

CASTRO-PAREDES, M. Política, educación y territorio en Chile (1950 - 2010): de las acciones colectivas a las acciones del mercado. Educación y Educadores, v. 15, n. 1, p. 97-114, 2012. https://doi.org/10.5294/edu.2012.15.1.6

. Códigos para el análisis de política educativa local en Chile: temas pendientes. Ensaio: Avaliação e Políticas Públicas em Educação, v. 18, n. 67, p. 189-213, abr.-jun. 2010. https://dx.doi.org/10.1590/S0104-40362010000200002p

DONOSO, S.; CASTRO, M.; ALARCÓN, J. Aspectos críticos en las propuestas sobre una nueva arquitectura de la educación pública chilena. Estudios Pedagógicos, v. 41, n. 2, p. 305-24, 2015. https://doi.org/10.4067/S0718-07052015000200018

ESCOBAR, D. Pedro Aguirre Cerda y el Frente Popular: un intento modernizador de la educación chilena. Revista de Historia de la Educación, v.2, p. 9-26, 1996.

ESPINOZA, O. La crisis del sistema educacional en Chile y el proceso de reforma desde una perspectiva sociopolitica (1939-1952). 1986. 182 p. Tesis (Licenciatura en Historia) - Universidad de Chile, Santiago, 1986.

HENRÍQUEZ, R. En estado sólido: políticas y politización en la construcción estatal. Chile 1920-1950. Santiago: Ediciones UC, 2014.

ILLÁNES, M. A. Cuerpo y sangre de la política: la construcción histórica de las Visitadoras sociales (1887-1940). Santiago: LOM, 2006.

. En el nombre del pueblo, del Estado y de la ciencia: Historia

social de la salud pública, Chile, 1880/1973 (Hacia una historia social del siglo XX). Santiago: Ministerio de Salud-Protege Red de Protección Social, 2010.

LATORRE, G. Educación para la democracia, Revista de Educación, v. 33, p. 472- 6, 1945 b.

. La experimentación educacional en Chile. Revista de Educación, v. 27 , p. $39-44,1945 \mathrm{a}$.

MARTNER, C. Contribuciones y carencias del discurso educacional de la izquierda chilena: 1938-1952. Santiago: ECO Educación y Comunicaciones, 1986. 
MOULIÁN, T. Fracturas: de Pedro Aguirre Cerda a Salvador Allende 19381973. Santiago: LOM, 2006.

NÚÑEZ, I. Biología y educación: los reformadores funcionalistas. Chile, 1931-1948. Cuadernos de Historia de la Educación, v. 1, p. 65- 86, 2013.

. La producción de conocimiento acerca de la educación escolar chilena (1907-1957), CPEIP, Santiago, Chile, 2002.

.Hacia un paradigma de reformas: La experiencia chilena.

Pensamiento Educativo, v. 17, n. 2, p. 173-89,1995.

.La descentralización de las reformas educacionales en Chile: 19401973. Santiago: PIIE, 1989.

. Gremios del magisterio: setenta años de historia, 1900-1970.

Santiago: Programa Interdisciplinario de Investigaciones en Educación, 1986.

OSANDÓN, L. El cambio educativo desde el aula, la comunidad y la familia (1930-1970). Santiago: Universidad Academia de Humanismo Cristiano. 2007.

POPKEWITZ, T. La historia del currículum: la educación en los Estados Unidos a principios del siglo XX, como tesis cultural acerca de lo que el niño es y debe ser. Profesorado. Revista de Currículum y Formación de Profesorado, v. 11, n. 3, p. 1-13, 2007.

2000.

. Sociología política se las reformas educativas. Madrid: Morata,

REPÚBLICA DE CHILE. Mensaje de S.E. la Presidenta de la República con el que inicia un proyecto de ley que crea el Sistema de Educación Pública y modifica otros cuerpos legales. Mensaje No 1174-363. Santiago, 02 de noviembre de 2015.

REYES, L.; TOLEDO, M. I.; EGAÑA, M. L. Ėcole, communauté et sujetenseignant. Le projet historique de la 'Escuela Consolidada Miguel Dávila Carson'. Chili, 1953-1977. Paedagogica Historica, v. 49, n. 2, p. 1-19, 2013.

RÍOS, J. A. Mensaje de S.E. El Presidente don Juan Antonio Ríos en la apertura del Congreso Nacional su Excelencia el 21 de mayo de 1942. Santiago: Imprensa Nacional. 
TIRONI, A. La ideología del Partido Radical en los años treinta. Santiago: Ediciones Universidad Católica, 1983.

TORO, P. ¿Técnicos de la política y del alma? Un episodio en las discusiones sobre políticas de educación secundaria en Chile y la instalación de la orientación escolar a mediados del siglo XX. In GONZÁLEZ PÉREZ, T. (ed.). Templos del saber: discursos políticos y utopías educativas. Madrid: Mercurio, 2015. p.313-36.

URETA, J. Mujeres y sus percepciones sobre la escolarización campesina durante los gobiernos radicales, 1938-195: rapel de navidad. Cuadernos Chilenos de Historia de la Educación, n. 3, p. 65-89, 2015.

VIDELA, L. Lautaro Videla Stefoni: relato de vida. Santiago: PIIE, 2010.

ZEMELMAN, M.; JARA, I. Seis episodios de la Educación chilena: 19201965. Santiago: Ediciones Facultad de Filosofía y Humanidades, Universidad de Chile, 2006.

\section{Informações dos autores}

Graciela Rubio: Doctora en Educación. Académica del Instituto de Historia y Ciencias Sociales, Universidad de Valparaíso. Contacto: graciela.rubio@uv.cl

Luis Osandón: Doctor en Ciencias de la Educación. Académico Departamento de Estudios Pedagógicos, Universidad de Chile. Contacto: luis.osandon@uchile.cl

Francisca Quinteros: Licenciada en Historia. Profesora de Historia y Ciencias Sociales. Red-Q. Corporación de Educación Pública de Quillota. Contacto: mfranciscaqf@gmail.com 